\title{
THE QUEEN'S UNIVERSITY OF BELFAST
}

\section{NEW PHYSICS BUILDING}

$\mathrm{T}$ HE old physics building at the Queen's University of Belfast, which was built shortly before the First World War, has become increasingly inadequate for the needs of the Department since 1945. Temporary extra accommodation has been provided in two groups of three huts and a house, but these were scattered and have shortly to be taken down or used for other purposes. They have now been replaced by a substantial extension to the old building, which was opened by H.M. Queen Elizabeth, the Queen Mother, on April 6.

The new building, which is seen from the north in Fig. 1, is joined to the old building by two eurved corridors (beyond the left) at ground-floor and basement levels. It occupies most of the space along the city park boundary between the University's main assembly hall (at the right) and the old physics building. The principal part is a four-storey L-shaped structure concave to the boundary, with, under part of its area, a large sub-basement boiler house serving a number of buildings, and a smaller ventilating-plant room for the basement and ground-floor of the new physics building. There are also tank rooms and a second ventilating plant on the roof, and a new workshop connected to the lower link corridor, between the park boundary and the old building, but structurally separate from the latter. Goods can be delivered from the rear of the building to a two-ton lift giving access to most parts of both the old and new buildings.
The main store-rooms are located off the link corridors. Water and gas feeds are generous, and the central switch-room is supplied from an individual $500-\mathrm{kW}$. sub-station the capacity of which can be doubled later if necessary.

The new building has two lecture rooms. The larger, seating 280 , is situated at the south-west end. As it will also be used for general university purposes, it has a separate entrance and separate services from the rest of the building, and contains a number of projection units which are not at present usually considered necessary for physics teaching. The smaller, seating 100 , is on the first floor above a groundfloor library and reading room and the boiler house.

The ground, first and second floors will carry uniform loads of approaching 240, 180 and $120 \mathrm{lb} . / \mathrm{sq}$. ft. respectively. The bulk of the room heating in all three of these floors and the basement is by hot water circulating in acoustically treated ceiling panels. The layout is such that the uses of most sections of the building can be varied substantially. The initial allocation of space will probably be: basement, research and service rooms; ground floor, office, staff and research rooms; first floor, third- and fourth-year undergraduate teaching laboratories; second floor, second-year undergraduate teaching laboratorios.

The old building is to be rehabilitated during the session 1962-63. When it is again available, the

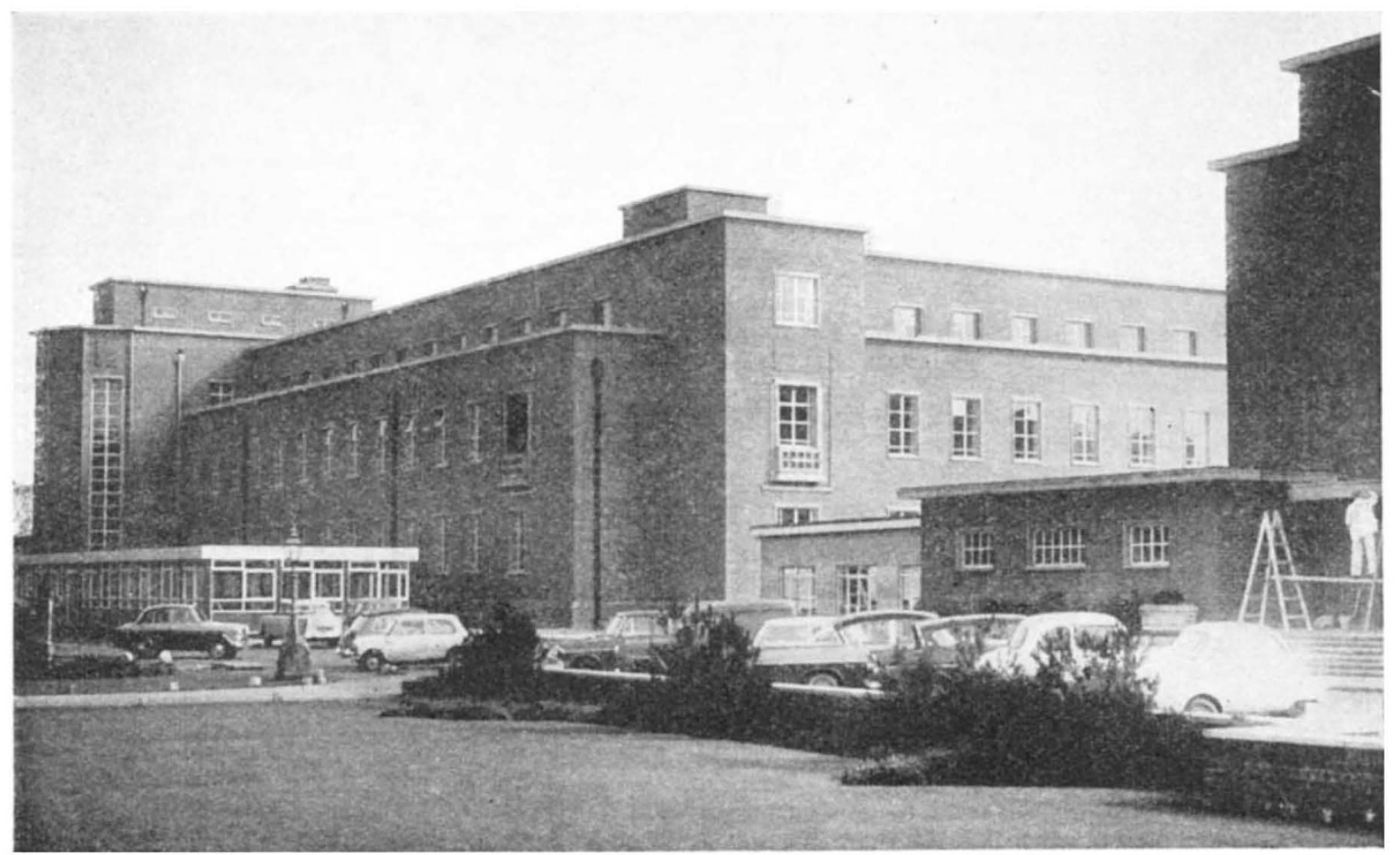

Fig. 1. Physics Extension Building, Queen's University of Belfast. The building to the right is the University assembly hall, the

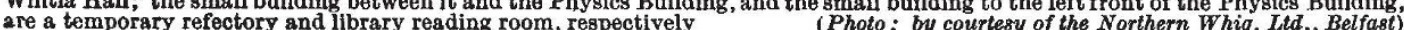


first floor of this will be used for the first-year undergraduate teaching laboratory. The total useful floor space in the old and new building will be somewhat over $60,000 \mathrm{sq}$. ft. The number of physics students in all years has been nearly 1,000 in the session 1961-62; future numbers will depend on the University's policy about limitation.
The architect of the building was Mr. John MacGeagh, the principal contractors Messrs. F. B. McKee and Co., Ltd., and the engineering consultants Messrs. Oscar Faber and Partners. The Department's interests have been attended to by Dr. R. H. Sloane, reader in physics. The total cost has been about $£ 800,000$.

\section{EXPERIMENTAL TAXONOMY}

$\mathrm{T}$ HE annual symposium of the group for experimental taxonomy of the Linnean Society of London was held on March 2, at the Society's rooms in London. After a brief introduction from Prof. D. H. Valentine, the meeting began with a paper by Dr. D. M. Moore (University of Leicester), on "Speciation within Chilean Clarkias". The annual genus Clarkia contains somo 34 species in western North America, and a series of forms from central Chile and adjacent regions of Argentina which are presently included under $C$. tenella (Cav.) Lewis and Lewis. C. tenella is tetraploid and has been shown to be closely related to $C$. davyi of coastal California by Raven and Lewis, who suggested that South American plants resulted from trans-equatorial long-distance dispersal in late Pliocene or more recent time. Data were presented to illustrate the pattern of variation within the Chilean species of Clarkia and its correlation with the breeding system. It was suggested that the ancestral introduction was close to the largeflowered outcrosser, with $n=17$, which occurs in southern central Chile; and a scheme was outlined to suggest the derivation of the other South American forms from this type. Some populations of outcrossers, separated from the others and representing the southermmost occurrence of the genus, have lost a pair of chromosomes but are morphologically identical with the 17-chromosome form. Most differentiation was shown to be associated with the change to autogamy, which generally involves no change of chromosome number. Self-pollinated forms have the stamens and style of equal length; anthers and style mature simultaneously and are in close contact. The most widespread form has small flowers, is markedly self-pollinated and shows a whole range of biotypes usually differing slightly from one another, though occasional more extreme deviants are found. Populations intermediate morphologically between these small-flowered self-pollinaters and the outcrosser are facultatively outcrossing, though primarily self-pollinated, suggesting a gradual change to autogamy. Another entity sympatric with, but temporally quite isolated from, the outcrosser has acquired self-pollination without other marked morphological change. In only one case do selfpollinating plants show a different chromosome number, $2 n=28$; they are also remarkable for their yellow flowers, which are very rare in the genus. This scheme was discussed in relation to the frequent independent origin of self-pollinating from outcrossing forms within Clarkia.

The second paper, by Dr. A. J. S. Davies (Chester Beatty Institute), was entitled "A Cytogenetic Study of 28 Species of the Genus Lathyrus". "The genus as a whole contrains some 110 species oceupying marginal and open habitats. Many morphological characters are used in the comparison of phenotypes in the traditional taxonomy of the group, and evolutionary trends in some of these can be postulated. The bracts at the base of the pedicel provide a useful indication of whether a spocies is specialized or not: there is a trend from long leafy bracts, to shorter, to a state where they are represented by a tuft of hairs. The genus is predominantly diploid $(2 n=14)$ and gross chromosomal changes have probably not played a large part in its evolution. It is thought that there has been a tendency for chromosome-length to decrease and for the karyotype to become more asymmetrical, and this trend is associated with a decrease in plant size. Attempts have been made to cross fourteen of the annual species; and it has been shown that embryo abortion is the main barrier to interspecific hybridization. Hybrid plants have, however, been raised from four combinations of species. One of these was taken to the $F_{2}$ generation, and it was shown that at least four major gene loci are common to the parental species. Two of these genes, however, were modified in their expression in the $F_{2}$, indicating differences in the genetic background of the two species involved.

Dr. C. D. K. Cook (University of Liverpool) gave the next paper on "Variation in Ranunculus subg. Batrachium". He noted that the number of taxa recognized from the time of Linnæus to the present day ranged from 1 to 108 ; the number of now names per decade follows a normal curve of distribution. Much of the confusion in the group is due to the wide range of phenotypic plasticity shown by the species and the inability of workers to distinguish it, in the herbarium, from genotypic variation. In cultivation, a grcat deal of variation, both genotypic and phenotypic, is revealed. Thus, the achene number in both British (Isle of Wight) and Finnish (Helsinki) topodemes of $R$. baudotii varied from 10 to 60 ; but under experimental conditions, they differed in the average number of achenes produced in still and flowing water. Their total plasticity-range was, however, the same. and they are best regarded as two parts of a cline, with different ecological preferences. Extreme phenotypes occasionally become genetically fixed; an example is provided by plants of the alpine state of $R$. trichophyllus, some of which retain their original shape when eultivated in lowland conditions, and some of which revert to normal. The transition between capillary and laminar leaves in the group is always abrupt and is affected by length of day and temperature, but it is primarily undor genetic control. Many hybrids are known. Some are infertile but very persistent, for cxample, some pentaploids in the fluitans group. Other species form fertilo hybrids which are often unstable and unlikely to persist, but great variability in the $\mathrm{F}_{2} \mathrm{~s}$ has been demonstrated, and some of these, which differ greatly from their parents, may occasionally be able to invade new habitats.

Dr. A. J. F. Smith (University College, Swansea) then gave a paper on "Variation in Melampyrum 